F. CHANG, S, WANG, Z, ZHAO, L, WANG, T, CHENG, G, LIU* (SHANGHAI NORMAL UNIVERSITY, P. R. OF CHINA)

Enantioselective Dual-Catalysis: A Sequential Michael Addition/Asymmetric Transfer Hydrogenation of $\alpha$-Nitrosulfone and Enones

ACS Catal. 2020, 10, 10381-10389, DOI: 10.1021/acscatal.0c01559.

\title{
One-Pot Two-Step Catalytic Asymmetric Michael Addition/Hydrogenation
}
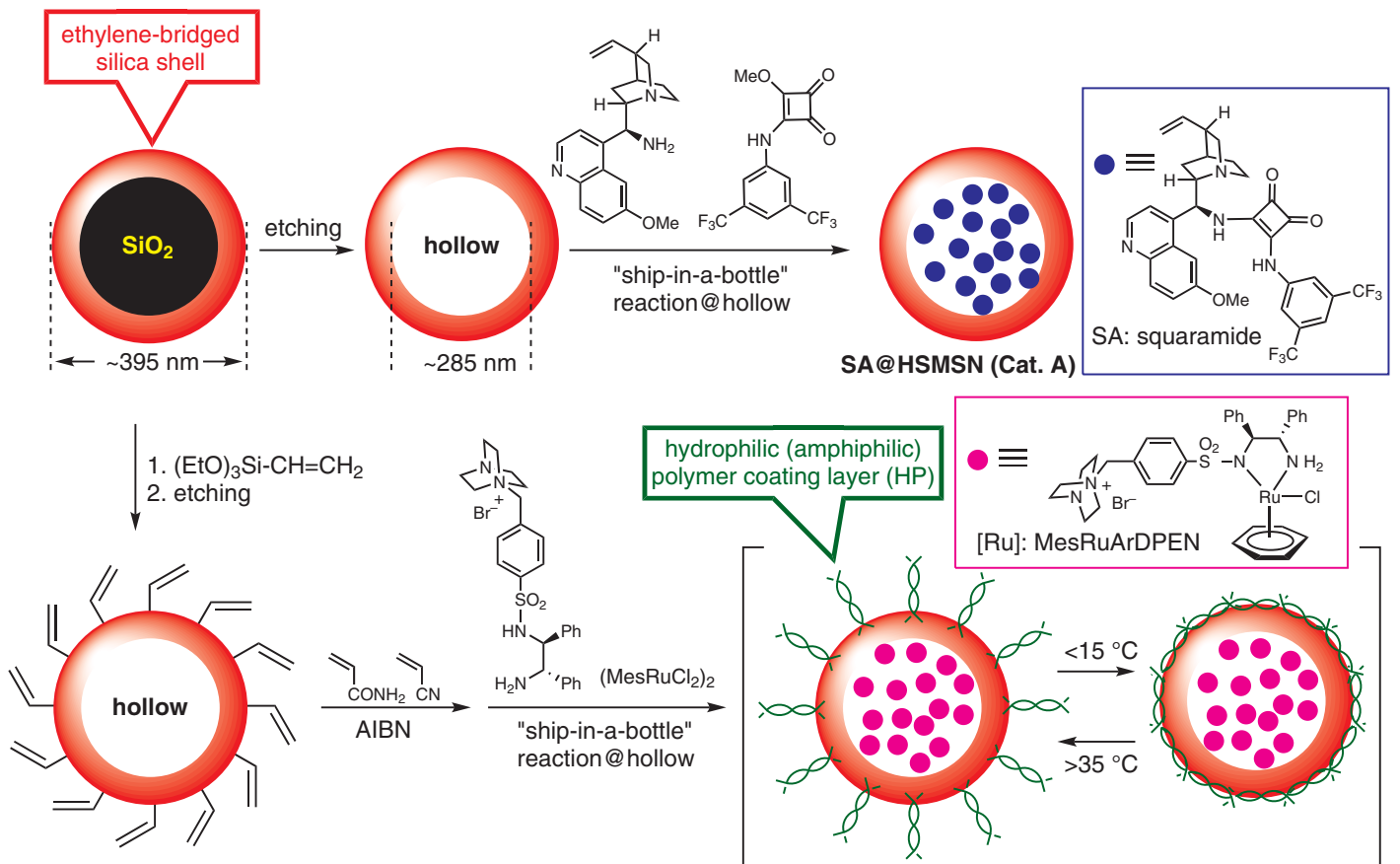

HSMSN = hollow-shell-mesostructured silica nanoparticle

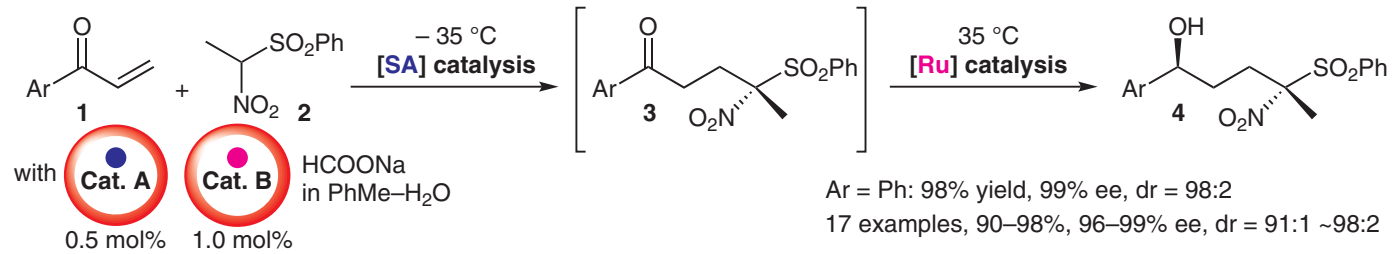

Significance: A one-pot two-step asymmetric Michael addition-transfer hydrogenation co-catalyzed by an immobilized organocatalyst [SA@HSMSN (Cat. A)] and a Ru complex catalyst $\{[R u] @ H S M S N /$ $\mathrm{HP}$ (Cat. B) \} was developed. The reaction of enone 1 and nitro sulfone $\mathbf{2}$ in the presence of Cat. A, Cat. B, and $\mathrm{HCO}_{2} \mathrm{Na}$ gave the corresponding alcohols 4 in excellent chemical yields and with high diastereoselectivity (96-99\% ee).

\section{Category}

Polymer-Supported

Synthesis

\section{Key words}

dual catalysis

one-pot synthesis

organocatalysis

ruthenium catalysis

asymmetric catalysis

Michael addition

Synfact is of the Month
Comment: Squaramide and MesRuArDPEN were immobilized in hollow-shell-mesostructured silica nanoparticles without or with a hydrophilic polymer coating to form Cat. A and Cat. B, respectively. Cat. A promoted the Michael addition at $-35^{\circ} \mathrm{C}$, and Cat. B catalyzed the transfer hydrogenation at $35^{\circ} \mathrm{C}$, to realize temperature-dependent control of the sequential dual-catalytic process. 